\title{
The effect of the humidifier on sore throat and cough after thyroidectomy
}

\author{
Tae Hyeng Jung, Jeong-Ho Rho, Jin Hwan Hwang, Jong-Hyuk Lee, Seung-Cheol Cha, and \\ Seong Chang Woo
}

Department of Anesthesiology and Pain Medicine, Eulji University Hospital, Daejeon, Korea

Background: This study was performed to determine the effects of a humidifier with heated wire circuits on the incidence and severity of postoperative sore throat (POST) and cough after thyroidectomy.

Methods: A total of 61 patients scheduled for elective thyroid surgery under general anesthesia were included in this prospective study. We randomized the patients in to two groups, "without active warming and humidification" (Group C) and "using a heated humidifier" (Group H). The patients were interviewed to obtain the POST and cough scores at 1, 6, 24 and 48 hours after thyroidectomy.

Results: The incidence of POST was significantly lower in Group H compared to Group C at 6 hours (57\% vs $84 \%$, $\mathrm{P}=0.041)$, 24 hours ( $37 \%$ vs $65 \%, \mathrm{P}=0.045)$, and 48 hours $(10 \%$ vs $52 \%, \mathrm{P}=0.001)$. Also the incidence of cough was significantly lower in Group $\mathrm{H}$ at 6 hours ( $27 \%$ vs $71 \%, \mathrm{P}=0.001)$, 24 hours ( $13 \%$ vs $45 \%, \mathrm{P}=0.015)$, and 48 hours $(7 \%$ vs $32 \%, \mathrm{P}=0.028$ ). The severity of POST was significantly lower in Group $\mathrm{H}$ at all times. In addition, the severity of cough was lower in Group $\mathrm{H}$ at other times except at 1 hour.

Conclusions: This result suggests that an active humidification of inspired gases may have the appreciable effect on reducing the incidence and severity of sore throat and cough after thyroid surgery using the endotracheal tube. (Korean J Anesthesiol 2011; 61: 470-474)

Key Words: Cough, Endotracheal intubation, Humidification, Sore throat, Thyroidectomy.

Received: March 23, 2011. Revised: 1st, May 9, 2011; 2nd, May 24, 2011; 3rd, May 31, 2011; 4th, June 1, 2011. Accepted: June 6, 2011.

Corresponding author: Seong Chang Woo, M.D., Ph.D., Department of Anesthesiology and Pain Medicine, Eulji University Hospital, 1306, Dunsan 2-dong, Seo-gu, Daejeon 302-799, Korea. Tel: 82-42-611-3655, Fax: 82-42-611-3882, E-mail: woonoh@eulji.ac.kr

(c) This is an open-access article distributed under the terms of the Creative Commons Attribution Non-Commercial License (http:// creativecommons.org/licenses/by-nc/3.0/), which permits unrestricted non-commercial use, distribution, and reproduction in any medium, provided the original work is properly cited. 


\section{Introduction}

Postoperative sore throat (POST) is one of the common symptoms that occurs following surgery under general anesthesia, and is a feeling of discomfort that develops during the postoperative recovery period. It causes physical stress and can affect operation satisfaction and rate of recovery. POST may manifest in various forms following surgery, and it has been reported that POST may cause hoarse voice, swallowing difficulty, laryngitis, bronchitis and respiratory distress $[1,2]$. Since POST is spontaneously reduced within several days, it is of lesser interest to physicians.

The incidence of POST varies according to different reports, with a range between $14.4 \%$ and $80 \%$. POST is reported to be higher in patients that have undergone thyroid surgery as compared to other surgeries [3-5].

General anesthesia using the cool and dry anesthetic gas can also be one of the major causes of POST, hoarse voice and cough. The cool and dry anesthetic gas directly reaches the lower respiratory tract during mechanical ventilation after endotracheal intubation. It causes a decrease in heat and humidity, induces inflammation and irritates the tissue within the respiratory tract, and impairs the functions of cells lining the respiratory mucosa $[6,7]$. Various types of pharmacological and non-pharmacological methods have been examined to reduce the occurrence of POST [1,8-11].

Therefore, we attempted to assess the effectiveness of a heated humidifier on the pattern of POST and cough occurrence following thyroidectomy.

\section{Materials and Methods}

From patients scheduled for an elective thyroidectomy under general anesthesia, 64 adults aged between 20 and 60 years old and corresponded to the American Society of Anesthesiologists (ASA) physical status Class 1 or 2 were randomly selected and enrolled in our study. This study was approved by the Institutional Review Board (IRB) at our hospital and patients were recommended to submit a written informed consent following oral explanation. Of these patients, those who had throat pain preoperatively, presented with the symptoms of upper respiratory infection within the recent two weeks, had smoking history or a past history of taking treatments for chronic respiratory symptoms, had abnormalities on the chest radiography, experienced hyperthyroidism or hypothyroidism, in whom endotracheal intubation was attempted more than twice, or more than 15 seconds elapsed for the endotracheal intubation, as well as those in whom the operation time was shorter than two hours, were excluded from this study.

The sample size was calculated from the assumption that the incidence of POST was set at $80 \%$ based on the report by Kadri et al. [4]. In cases where a heated humidifier was used, it was aimed that the incidence should be lowered to $50 \%$. At a Type I error $(\sigma)$ of 0.05 and a statistical power of 0.90 , the number of patients who could be assigned to each group was calculated as 29 . We determined that the total number of patients was 32 considering the drop-outs. Thus, a total of 64 patients were enrolled in this study. Of patients who would be assigned to each group, patients who used a heated humidifier (Heated Circuit Kit ${ }^{\circledR}$, Acemedical, Korea) were assigned to Group H and those who used the general respiration circuit were assigned to Group C.

All patients were not pre-medicated. After monitoring with 3 lead EKG, noninvasive arterial blood pressure, and pulse oxymetry on arrival at the operation room, patients were given an intravascular injection of midazolam $0.05 \mathrm{mg} / \mathrm{kg}$. Patients were also recommended to perform spontaneous breathing using $100 \%$ oxygen. In addition, propofol and remifentanil were connected to a specialized device for target controlled infusion (TCI) (Base Primea Ochestra ${ }^{\circledR}$, Fresenius Vial, France). Thus, the effective concentrations were set at $3.0 \mu \mathrm{g} / \mathrm{ml}$ and $4.0 \mathrm{ng} /$ $\mathrm{ml}$, respectively, and the anesthesia was induced accordingly. Following the confirmation of loss of consciousness with the use of manual bagging using $100 \%$ oxygen $4 \mathrm{~L} / \mathrm{min}$, vecuronium 0.1 $\mathrm{mg} / \mathrm{kg}$ was administered. After 3 minutes later, with the use of an anode tube with an internal diameter of $7.5 \mathrm{~mm}$ in men and $7.0 \mathrm{~mm}$ in women, the endotracheal intubation was performed for less than 15 seconds. The tube cuff pressure was adjusted from 15 to $20 \mathrm{~cm} \mathrm{H}_{2} \mathrm{O}$ with the use of a barometer (Mallinckroft Medical, Athlone, Ireland). The cuff pressure was re-adjusted at 10-minute intervals Anesthesia was maintained such that the tidal volume (TV), respiratory rates, oxygen and medical air were set at $8 \mathrm{ml} / \mathrm{kg}, 10$ breaths $/ \mathrm{min}, 2 \mathrm{~L} / \mathrm{min}$ and $2 \mathrm{~L} / \mathrm{min}$, respectively. In addition, the end-tidal partial pressure of carbon dioxide was maintained at $35-40 \mathrm{mmHg}$. Twenty minutes prior to the completion of the surgical procedure, all patients were intravenously given ramosetron $0.3 \mathrm{mg}$ for the prevention of nausea and vomiting and ketolorac $30 \mathrm{mg}$ for postoperative pain control. After surgery, patients were intravenously given pyridostigmine $0.2 \mathrm{mg} / \mathrm{kg}$ and glycopyrrolate $0.008 \mathrm{mg} / \mathrm{kg}$. Also, the airway reflex recovered and extubation was performed.

The pattern of POST and cough were assessed at a recovery room after 1 hour. On postoperative 6, 24 and 48 hours, the study subjects were evaluated at a ward. The assessment of POST was done by scores according to the direct questionnaire survey proposed by Harding et al. [12] (Table 1).

All the data was expressed as mean \pm standard deviation. Statistical analysis was performed using SPSS 12.0 (SPSS Inc., Chicago, IL, USA). Between group differences in the age, height, weight, operation time and anesthetic time were made with 
the use of a t-test. Also, a comparison of the incidence of throat pain and cough was made with the use of a Chi-square test. In addition, the severity of POST and cough was performed using the Mann Whitney-u-test. A P value of $<0.05$ was considered statistically significant.

Table 1. Scoring System for Sore Throat and Cough

Please grade any sore throat you may have according to the following scale

0 No sore throat at any time since your operation.

1 Minimal sore throat, less severe than noted with a cold, occurring at any time.

2 Moderate sore throat, similar to that noted with a cold, occurring at any time.

3 Severe sore throat, more severe than noted with a cold, occurring at any time.

Please grade any cough you may have according to the following scale

0 No cough or scratchy throat occurring at any time since your operation.

1 Minimal scratchy throat or cough, less than noted with a cold, occurring at any time.

2 Moderate cough, as would be noted with a cold, occurring at any time.

3 Severe cough, greater than noted with a cold, occurring at any time.

Table 2. Demographic Data, Surgical and Anesthesia Data

\begin{tabular}{lcc}
\hline & Group C ( $\mathrm{n}=31)$ & Group H $(\mathrm{n}=30)$ \\
\hline Age $(\mathrm{yr})$ & $45.6 \pm 10.2$ & $43.7 \pm 7.9$ \\
Weight $(\mathrm{kg})$ & $60.5 \pm 9.3$ & $64.2 \pm 12.9$ \\
Height $(\mathrm{cm})$ & $157.1 \pm 5.7$ & $159.9 \pm 7.6$ \\
Duration of anesthesia (min) & $181.8 \pm 38.8$ & $168.3 \pm 38.1$ \\
Duration of operation (min) & $149.2 \pm 30.7$ & $148.0 \pm 38.6$ \\
Sex (M/F) & $2 / 29$ & $3 / 27$ \\
ASA class (I/II) & $23 / 8$ & $20 / 10$ \\
\hline
\end{tabular}

Values are as mean \pm SD or the number of patients (\%). Group C: control group, Group H: heated circuit group.

\section{Results}

The number of patients that were assigned to Group $\mathrm{C}$ and $\mathrm{H}$ were 31 and 30, respectively. Of a total of 64 subjects, 1 patient from Group $\mathrm{C}$ and 2 patients from Group $\mathrm{H}$ had an operation time of less than 2 hours. These patients were excluded from the current analysis. There were no significant differences in the demographic variables such as sex, age, weight and height between the two groups. Also, there were no significant differences in the anesthetic time between the two groups (Table 2).

On postoperative 1 hour, there was no significant difference in the incidence of POST between the two groups. However, on postoperative 6 hours ( $57 \%$ vs $84 \%, \mathrm{P}=0.041), 24$ hours $(37 \%$ vs $65 \%, \mathrm{P}=0.045)$ and 48 hours $(10 \%$ vs $52 \%, \mathrm{P}=0.001)$, the incidence of POST was significantly lower in Group H (Table 3).

In addition, on postoperative 1 hour, there was no significant difference in the incidence of cough between the two groups.

Table 4. Severity of Postoperative Sore Throat and Cough

\begin{tabular}{|c|c|c|}
\hline & Group C $(\mathrm{n}=31)$ & Group H $(n=30)$ \\
\hline \multicolumn{3}{|c|}{$1 \mathrm{~h}$ after tracheal extubation } \\
\hline Sore throat & $3 / 14 / 11 / 3$ & $8 / 17 / 3 / 2^{*}$ \\
\hline Cough & $9 / 20 / 2 / 0$ & $14 / 15 / 1 / 0$ \\
\hline \multicolumn{3}{|c|}{$6 \mathrm{~h}$ after tracheal extubation } \\
\hline Sore throat & $5 / 14 / 9 / 3$ & $13 / 13 / 2 / 2^{\dagger}$ \\
\hline Cough & $9 / 22 / 0 / 0$ & $22 / 7 / 1 / 0^{\dagger}$ \\
\hline \multicolumn{3}{|c|}{$24 \mathrm{~h}$ after tracheal extubation } \\
\hline Sore throat & $11 / 15 / 4 / 1$ & $19 / 11 / 0 / 0^{*}$ \\
\hline Cough & $17 / 14 / 0 / 0$ & $26 / 4 / 0 / 0^{\dagger}$ \\
\hline \multicolumn{3}{|c|}{$48 \mathrm{~h}$ after tracheal extubation } \\
\hline Sore throat & $15 / 13 / 3 / 0$ & $27 / 3 / 0 / 0^{\dagger}$ \\
\hline Cough & $21 / 10 / 0 / 0$ & $8 / 2 / 0 / 0^{*}$ \\
\hline \multicolumn{3}{|c|}{$\begin{array}{l}\text { Data are the actual numbers in each grade. Sore throat was graded } \\
\text { as: } 0 \text {, absent; } 1 \text {, minimal; } 2 \text {, moderate; } 3 \text {, severe. Cough was graded } \\
\text { as: } 0 \text {, absent; } 1 \text {, minimal; } 2 \text {, moderate; } 3 \text {, severe. Group C: control } \\
\text { group, Group H: used a heated circuit kit. }{ }^{*} \text { Denotes } \mathrm{P}<0.05 \text { during } \\
\text { inter-group between Group C vs. Group H. }{ }^{\dagger} \text { Denotes } \mathrm{P}<0.01 \text { during } \\
\text { inter-group between Group C vs. GroupH. }\end{array}$} \\
\hline
\end{tabular}

Table 3. Incidence of Postoperative Sore Throat and Cough

\begin{tabular}{|c|c|c|c|}
\hline & Group C $(\mathrm{n}=31)$ & Group H $(\mathrm{n}=30)$ & $P$ values \\
\hline \multicolumn{4}{|c|}{$1 \mathrm{~h}$ after tracheal extubation } \\
\hline Sore throat & $28 / 31(90 \%)$ & $22 / 30(73 \%)$ & 0.248 \\
\hline Cough & $22 / 31(71 \%)$ & $16 / 30(53 \%)$ & 0.248 \\
\hline \multicolumn{4}{|c|}{$6 \mathrm{~h}$ after tracheal extubation } \\
\hline Sore throat & $26 / 31(84 \%)$ & $17 / 30(57 \%)$ & 0.041 \\
\hline Cough & 22/31 (71\%) & $8 / 30(27 \%)$ & 0.001 \\
\hline \multicolumn{4}{|c|}{$24 \mathrm{~h}$ after tracheal extubation } \\
\hline Sore throat & 20/31 (65\%) & $11 / 30(37 \%)$ & 0.045 \\
\hline Cough & $14 / 31(45 \%)$ & $4 / 30(13 \%)$ & 0.015 \\
\hline \multicolumn{4}{|c|}{$48 \mathrm{~h}$ after tracheal extubation } \\
\hline Sore throat & $16 / 31(52 \%)$ & $3 / 30(10 \%)$ & 0.001 \\
\hline Cough & $10 / 31(32 \%)$ & $2 / 30(7 \%)$ & 0.028 \\
\hline
\end{tabular}

Values are number of patients and \%. Group C: control group, Group H: heated circuit group. 
However, on postoperative 6 hours $(27 \%$ vs $71 \%, \mathrm{P}=0.001)$, 24 hours ( $13 \%$ vs $45 \%, \mathrm{P}=0.015)$ and 48 hours $(7 \%$ vs $32 \%, \mathrm{P}=$ 0.028 ), the incidence of cough was significantly lower in Group $\mathrm{H}$ (Table 3). With regards to the severity of POST, it was found to be significantly lower on all the postoperative times in Group $\mathrm{H}$. In addition, the severity of cough was found to be significantly lower in Group H on postoperative 6, 24 and 48 hours (Table 4).

\section{Discussion}

In our study, we evaluated the effectiveness of the active warming and humidification of inhaled gas in patients that underwent thyroid surgery that lasted over 2 hours of operation time. This showed that the incidence of POST and the severity of cough were significantly lower in Group $\mathrm{H}$, which implied that the warming and humidification of inhaled gas during the operation were effective.

Christensen et al. [3] reported that the incidence of POST was $61.8 \%$ and this was significantly higher than those who underwent gynecologic surgery, orthopedic surgery, mastectomy and abdominal surgery. Kadri et al. [4] and Hisham et al. [5] also reported that it was $80 \%$ and $68 \%$, respectively. Our results show that the incidence of POST was $90.3 \%$ on postoperative 1 hour in Group C. This value was significantly higher than in other studies. Also, it was relatively higher in patients that underwent thyroid surgery compared to other surgeries.

Kadri et al. [4] reported the incidence of POST was dependent on the types of thyroid surgery. According to these, it was $59.6 \%$ following partial thyroidectomy, $87.7 \%$ following subtotal thyroidectomy and $100 \%$ following total thyroidectomy. Hisham et al. [5] reported that it was $52 \%$ following partial thyroidectomy. However, it was found to be $81 \%$ following total thyroidectomy with modified radical neck dissection or total thyroidectomy without modified radical neck dissection. In our study, the incidence of POST was $83.9 \%$ following total thyroidectomy with modified radical neck dissection or total thyroidectomy without modified radical neck dissection. These findings were similar to other studies. However, because of the small number of patients who underwent partial thyroidectomy in our study, we were not able to compare with partial thyroidectomy and other surgical methods except partial thyroidectomy.

It is possible that the variability of POST incidence arises from differences in the kinds of anesthesia, the technical expertise of anesthesiologist, the definition about sore throat and interviews with patients.

Firstly, it can be predicted that the subjectivity about sore throat and the methods of inquiry and interview may further increase the discrepancy in POST incidence. In our study, questionnaires were generated based on a previous report by
Harding et al. [12]. The data had been collected from the direct questionnaire methods. According to that, of 129 patients who were interviewed through the indirect questionnaire methods, 2 patients were reported with POST. Of 113 patients who were interviewed through the direct questionnaire methods, 28 patients were reported with POST. These results indicate that there was a difference in the incidence of POST depending on the types of questionnaire methods. In particular, due to the neck area at the surgical site, it was necessary to confirm whether the neck pain did not originate from the surgical site in our study. This would rule out the possibility that patients confused neck pain with pain from the surgical site during the interview. This was based on a questionnaire through the direct inquiry. Our findings showed that patients who underwent thyroidectomy could be included in a preliminary questionnaire.

In addition, It has been reported that POST can be perceived as symptoms such as continuous neck pain, hoarse voice, swallowing difficulty, dry mouth, a feeling of discomfort in specific parts of the body (laryngitis and bronchitis) and cough $[1,2]$.

According to Ayoub et al. [8], Tazeh-kand et al. [9] and Sumathi et al. [10], patients who underwent the endotracheal intubation experienced hoarse voice at a higher incidence than POST on postoperative 1 hour. Cough occurred at a lower incidence than POST according to all the three studies.

In addition, following a comparison between throat pain and cough symptoms, the incidence of throat pain was higher than that of cough on postoperative 1 hour. In our study of a comparison between throat pain and cough, the incidence of POST was relatively higher than cough. These results were identical to previous studies [8-10].

However, Herlevsen et al. [11] examined the incidence of individual symptoms such as sore throat (19\%), hoarse voice (21\%) and cough (10\%), and the number of patients who complained of more than one of these three symptoms (38\%). These results indicate that the individual symptoms may overlap with the symptoms of sore throat. Though several studies have examined throat pain as different from the individual symptoms such as hoarse voice, cough, swallowing difficulty and dry mouth, individual symptoms may still be confused with sore throat. As a result, sore throat may not be clearly defined in several reports. This indicates that the incidence of POST may vary depending on the different reports.

POST is one of the most common outcomes following general anesthesia. According to Higgins et al. [13], the incidence of POST was found to be $3.3 \%$ even in patients using a face mask. As described here, it can be inferred that the symptoms of throat pain were suggestive of various expressions of inflammation due to the damage of mucosa that occurs in the oral cavity as 
well as the pharynx, larynx and other parts of the lower respiratory tract.

The effects of active warming and humidifying associated with POST were first identified by Kim et al. [14]. They showed that there were no clinical effects on reducing the incidence and severity of POST in patients using a laryngeal mask for less than 2 hours. In addition, there were no other reports on endotracheal intubation.

Accordingly, by using the endotracheal intubation in patients who underwent the thyroidectomy for more than 2 hours, we evaluated the effects of using the warming and humidifying circuit as the non-pharmacological treatment method in reducing the incidence of POST. In general, studies about the warming and humidifying circuit have determined the effects on protection of the structure and functions of mucociliary cells lining the bronchus. The criteria for recommending warming and humidification in low-flow anesthesia were established by Branson et al. [7]. It was shown that there were effects in maintaining the absolute humidity at least $12-15 \mathrm{mgH}_{2} \mathrm{O} / \mathrm{L}$. In addition, Kilgour et al. [15] recently reported that the warming and humidifying was not sufficient when the relative humidity was maintained as $100 \%$ at $30^{\circ} \mathrm{C}$ and $34^{\circ} \mathrm{C}$ under artificial ventilation for more than 6 hours in an animal experimental model. However, Stone et al. [16] reported that the warming and humidifying methods at $37^{\circ} \mathrm{C}$ and a relative humidity of $100 \%$ were effective in patients who were supposed to have surgery for over 3 hours. This report showed that warming over $37^{\circ} \mathrm{C}$ was an important factor. In the current study, the status of warming and humidifying in our study could be predicted based on the reports by Park et al. [6] using the same heated humidifier circuit. Similar to them, the total amount of flow of anesthetic gas was $4 \mathrm{~L} / \mathrm{min}$ in our study. In Group $\mathrm{C}$ and $\mathrm{H}$, the temperature, relative humidity and absolute humidity of inhaled gas were found to be $30.4 \pm 1.8^{\circ} \mathrm{C}$ vs $36.2 \pm 1.0^{\circ} \mathrm{C}, 37.9 \pm 6.0 \%$ vs $89.5 \pm 4.8 \%$ and $10.7 \pm 2.3 \mathrm{mgH}_{2} \mathrm{O} / \mathrm{L}$ vs $36.2 \pm 0.6 \mathrm{mgH}_{2} \mathrm{O} / \mathrm{L}$ in the corresponding order. The temperature and relative humidity of inhaled gas were a little lower than the recommended criteria. However, the absolute humidity fulfilled the recommended criteria as compared to Group C.

For warming and humidifying the inhaled gas, in addition to the methods for using the heated humidifier circuit, there were the low-flow anesthesia or closed circuit methods, as well as the heat and humidity exchanger. Further studies are needed to compare the clinical effects of these additional methods [17].

In conclusion, based on the results that the incidence and severity of POST and cough following the thyroidectomy with using the endotracheal intubation over 2 hours, we suggest that the use of a heated humidifier may be an effective modality that can prevent the occurrence of POST and cough.

\section{References}

1. McHardy FE, Chung F. Postoperative sore throat: cause, prevention and treatment. Anaesthesia 1999; 54: 444-53.

2. Miller KA, Harkin CP, Bailey PL. Postoperative tracheal extubation. Anesth Analg 1995; 80: 149-72.

3. Christensen AM, Willemoes-Larsen H, Lundby L, Jakobsen KB. Postoperative throat complaints after tracheal intubation. Br J Anaesth 1994; 73: 786-7.

4. Kadri IA, Khanzada TW, Samad A. Post-thyroidectomy sore throat: a common problem. Par J Med Sci 2009; 25: 408-12.

5. Hisham AN, Roshilla H, Aina EN. Post-thyroidectomy sore throat following endotracheal intubation. ANZ J Surg 2001; 71: 669-71.

6. Park HG, Im JS, Park JS, Joe JK, Lee S, Yon JH, et al. A comparative evaluation of humidifier with heated wire breathing circuit under general anesthesia. Korean J Anesthesiol 2009; 57: 32-7.

7. Branson RD, Campbell RS, Davis K, Porembka DT. Anaesthesia circuits, humidity output, and mucocillary structure and function. Anaesth Intensive Care 1998; 26: 178-83.

8. Ayoub CM, Ghobashy A, Koch ME, McGrimley L, Pascale V, Qadir $\mathrm{S}$, et al. Widespread application of topical steroids to decrease sore throat, hoarseness, and cough after tracheal intubation. Anesth Analg 1998; 87: 714-6.

9. Tazeh-kand NF, Eslami B, Mohammdian K. Inhaled fluticasone propionate reduces postoperative sore throat, cough, and hoarseness. Anesth Analg 2010; 111: 895-8.

10. Sumathi PA, Shenoy T, Ambareesha M. Krishna M. Controlled comparison between betamethasone gel and lidocaine jelly applied over tracheal tube to reduce postoperative sore throat, cough, and hoarseness of voice. Br J Anaesth 2008; 100: 215-8.

11. Herlevsen P, Bredahi C, Hindsholm K, Kruhøffer PK. Prophylactic laryngo-tracheal aerosolized lidocaine against postoperative sore throat. Acta Anaesthesiol Scand 1992; 36: 505-7.

12. Harding MB, Registrar FK, McVey MB. Interveiw method incidence of postoperative sore throat. Anaesthesia 1987; 42: 1104-7.

13. Higgins PP, Chung F, Mezei G. Postoperative sore throat after ambulatory surgery. Br J Anaesth 2002; 88: 582-4.

14. Kim DK, Rhee KY, Kwon WK, Kim TY, Kang JE. A heated humidifier does not reduce laryngo-pharyngeal complaints after brief laryngeal mask anesthesia. Can J Anaesth 2007; 54: 134-40.

15. Kilgour E, Rankin N, Ryan S, Pack R. Mucocillary function deteriorates in the clinical rage of inspired air temperature and humidity. Intensive Care Med 2004; 30: 1491-4.

16. Stone DR, Downs JB, Paul WL, Perkins HM. Adult body temperature and heated humidification of anesthetic gases during general anesthesia. Anesth Analg 1981; 60: 736-41.

17. Lu CC, Ho ST, Liaw WJ, Chen RM, Chen TL, Lin CY. The effect of heat-moisture exchange and closed-circuit technique on airway climate during desflurane anesthesia. J Anesth 2008; 22: 7-12. 